\title{
Clinical Features of Excyclotorsion in the Non- Paretic Eye of Patients with Congenital Unilateral Superior Oblique Palsy
}

\section{Eun-Hyang Cha}

Korea University Medical Center

Suk-Gyu Ha ( $\nabla$ sukgyu.ha@gmail.com )

Korea University Medical Center

\section{Youngwoo Suh}

Korea University Medical Center

\section{Seung-Hyun Kim}

Korea University Medical Center

\section{Research Article}

Keywords: age, excyclotorsion, fixation, surgery, superior oblique palsy

Posted Date: December 22nd, 2021

DOI: https://doi.org/10.21203/rs.3.rs-821380/v2

License: (c) This work is licensed under a Creative Commons Attribution 4.0 International License.

Read Full License

Version of Record: A version of this preprint was published at BMC Ophthalmology on March 16th, 2022. See the published version at https://doi.org/10.1186/s12886-022-02339-5. 


\section{Abstract}

\section{Background}

To investigate preoperative clinical features and postoperative results according to the correspondence between excyclotorsion and the paretic eye in patients with congenital unilateral superior oblique palsy (USOP).

\section{Methods}

A retrospective review of medical charts was performed. The patients were divided into the accordance (ocular excyclotorsion in the paretic eye) and discordance (ocular excyclotorsion in the non-paretic eye) groups. The degree of excyclotorsion (scale, $0-4$ ) was measured. Age, sex, hypertropia at the primary position, fixation preference, inferior oblique overaction, and degree of excyclotorsion were measured.

\section{Results}

Ninety-eight patients were included in this study. There were $70(71.4 \%)$ and 28 patients $(28.6 \%)$ in the accordance and discordance groups. Sixteen patients (22.9\%) in the accordance group and 12 patients $(42.9 \%)$ in the discordance group were aged under 2 years $(p=0.04)$. A fixation preference of the paretic eye was observed in $2(2.9 \%)$ and $8(28.6 \%)$ patients in the accordance and discordance groups ( $p<$ $0.01)$. The postoperative degree of excyclotorsion in the accordance group $(0.14 \pm 0.39)$ was lower than that in the discordance group $(0.28 \pm 0.71)(p=0.01)$. The residual postoperative excyclotorsion $(>1)$ in the discordance group were observed in the discordance group (14 patients, 50\%) and accordance group (16 patients, $22.9 \%)(p=0.01)$.

\section{Conclusion}

Preoperative discordance between excyclotorsion and the paretic eye was observed in patients who were under 2 years of age and preferred fixation of the paretic eye. The postoperative degree of excyclotorsion was lower in the accordance group.

\section{Introduction}

Unilateral superior oblique palsy (USOP) may be congenital or acquired. Congenital USOP is the most common form of USOP, accounting for approximately $33-69.2 \%$ of the cases. A common cause of acquired USOP is trauma followed by vascular diseases, such as hypertension, diabetes, tumor, iatrogenic factors, and congenital conditions.[1]

Congenital USOP is one of the most common forms of paralytic cyclovertical strabismus,[2-5] which can be accompanied by underaction of the superior oblique and overaction of the ipsilateral inferior oblique muscle. Abnormal head posture and facial asymmetry could be strong evidence of USOP in patients presenting with a positive Bielschowsky head-tilt test result.[6-8] The degree of facial asymmetry is 
usually proportional to the degree of head-tilt such that early strabismus surgery to correct the head-tilt may help prevent facial asymmetry in congenital SOP. Patients with USOP typically have hypertropia of the paretic eye, which is combined with horizontal strabismus in $72.2 \%$ of the cases.[9]

As the primary function of the superior oblique is incyclotorsion, paralysis of the muscle can cause significant ocular excyclotorsion of the paretic eye, which is one of the typical clinical manifestations of USOP. However, excyclotorsion is not always present in the paretic eye. Several studies have found that approximately $25 \%$ of the patients with USOP had ocular excyclotorsion in the non-paretic eye.[10-13]

Although it is unclear why ocular excyclotorsion is present in non-paretic eyes, several studies have found that fixation preference[14] and neural adaptation[15-17] may have a clinically significant influence on ocular excyclotorsion in non-paretic eyes.

In this study, we aimed to assess the clinical features associated with the correspondence of paretic eyes and excyclotorsion in USOP, and investigate postoperative changes in ocular excyclotorsion in USOP.

\section{Material And Methods}

\section{Patients}

This study was approved by the Institutional Review Board of Korea University Medical Center. It adhered to tenets of the Declaration of Helsinki. Written informed consent was obtained from all patients and their guardians. We retrospectively reviewed the medical records of 98 consecutive patients with congenital USOP diagnosed between 2001 and 2015 at the Department of Ophthalmology, Korea University Medical Center. The diagnosis of USOP was based on hypertropia, apparent elevation and under-depression in adduction of the paretic eye, anomalous head posture, or a positive Bielschowsky head-tilt test. All enrolled patients underwent full ophthalmic examination including visual acuity, refraction test, ocular movement, fixation preference,[18] scale of superior oblique underaction (SOUA) and inferior oblique overaction(IOOA), angle of deviation in the alternate prism cover test (prism diopters, PD), the Bielschowsky head-tilt test, presence of amblyopia or dissociated vertical deviation (DVD), and fundus examination.

Amblyopia was defined as a best-corrected visual acuity of $6 / 9$ or worse that was not directly attributable to any underlying structural abnormality of the eye or visual pathway. The exclusion criteria included acquired (masked) bilateral superior oblique palsy during ophthalmic examination, previous ocular surgery, history of head trauma, cerebrovascular diseases, and neurological disorders.

\section{Measurements}

The SOUA and IOOA were assessed using a -4 to +4 scale. The minus and plus values indicate underaction and overaction, respectively. The scales were documented before the operation and at each postoperative visit. SOUA was graded from -1 to -4 as follows: -1 , mild downward deviation of the pupil from the horizontal line in adduction; -2, lower margin of the pupil was aligned to the margin of the lower 
lid in adduction; -3 , inferior half of the pupil was covered by the lower lid in adduction; and -4 , the entire pupil was covered by the lower lid in adduction. IOOA was graded from +1 to +4 as follows: +1 , mild upward deviation of the pupil from the horizontal line in adduction; +2 , upper margin of the pupil was aligned to the margin of the upper lid in adduction; +3 , superior half of the pupil was covered by the upper lid in adduction; and +4 , the entire pupil was covered by the upper lid in adduction.

Fundus examination was performed to measure the degree of excyclotorsion using a fundus camera (TRC-50DX, Topcon Medical System, Tokyo, Japan) or indirect ophthalmoscope before and after the operation. The degree of excyclotorsion was measured using the Guyton grading scale.[19] Values +1 to +4 represent excyclotorsion and values -1 to -4 represent incyclotorsion based on the classification. When a horizontal line passed through the fovea within the inferior one-third of the disc, it was considered a normal range of torsion. If the vertical position of the fovea was located below the center of the optic disc, the excyclotorsion was graded from +1 to +4 .

Surgical procedures performed in this study included inferior oblique recession (12-14 mm) or ipsilateral superior rectus recession with or without superior rectus recession (>15 PD of hypertropia in the primary position) based on the preoperative amount of hypertropia at the primary position. Postoperative examinations were performed at 1, 3, 6, and 12 months, and then routinely at 1 -year intervals. All measurements were compared between pre- and postoperative final visits. Patients who were followed-up for at least 6 months postoperatively were included.

All patients were divided into the accordance (preoperative fundus ocular excyclotorsion in the paretic eye) and discordance (preoperative ocular excyclotorsion in the non-paretic eye) groups. The pre- and postoperative clinical features and the degree and change in excyclotorsion were compared between the accordance and discordance groups.

\section{Statistical analysis}

Statistical analysis was conducted using SPSS version 21.0 (IBM Corporation, Armonk, NY, USA). To assess the differences between the two groups, we used the Mann-Whitney test and Fisher's exact test. Statistical significance was set at $p<0.05$.

\section{Results}

A total of 98 patients who met the eligibility criteria were included in the study. There were 70 patients $(71.4 \%)$ in the accordance group and 28 patients $(28.6 \%)$ in the discordance group. The mean ages in the accordance and discordance groups were $9.2 \pm 12.7$ years ( $1-62$ years) and $7.5 \pm 8.9$ years (1-31 years), respectively $(p=0.17)$. Hypertropia in the primary position was $13.1 \pm 12.8 P D(5-35 P D)$ in the accordance group and $13.0 \pm 9.1$ PD (4-45 PD) in the discordance group $(p=0.82)$ (Table 1). There was no statistically significant difference between the two groups with regard to sex and the prevalence of amblyopia and DVD ( $p>0.05$, all). There were $12(42.9 \%)$ and $16(22.9 \%)$ patients aged $<2$ years in the 
accordance and discordance groups, respectively $(p=0.04)$. Table 1 shows the demographic details of the participants. 
Table 1

Basic demographics

Accordance group

Discordance group

P

\begin{tabular}{|llll}
\hline Number of patients, $\mathrm{n}(\%)$ & $70(71.4)$ & $28(28.6)$ & $<0.01^{\mathrm{a}}$ \\
\hline Age, years, $\mathrm{n}(\%)$ & $9.2 \pm 12.7$ & $7.5 \pm 8.9$ & $0.17^{\mathrm{a}}$ \\
\hline$<2$ & $(1-62)$ & $(1-31)$ & $0.04^{\mathrm{b}}$ \\
\hline $2-10$ & $16(22.9)$ & $12(42.9)$ & \\
\hline $11-17$ & $26(37.1)$ & $6(21.4)$ & \\
\hline$\geq 18$ & $20(28.6)$ & $4(14.3)$ & $0.11^{\mathrm{b}}$ \\
\hline Male sex, $\mathrm{n}(\%)$ & $8(11.4)$ & $6(21.4)$ & $0.35^{\mathrm{b}}$ \\
\hline Amblyopia, $\mathrm{n}(\%)$ & $53(75.7)$ & $17(60.7)$ & nil \\
\hline DVD, $\mathrm{n}(\%)$ & $3(4.5)$ & $2(7.1)$ & $0.29^{\mathrm{b}}$
\end{tabular}

${ }^{a}$ Mann-Whitney test, ${ }^{b}$ Fisher's exact test, DVD = dissociated vertical deviation

Table 2. Clinical characteristics in the accordance and discordance groups

\begin{tabular}{llll} 
Parameters & Accordance group & Discordance group & $\mathrm{p}$ \\
$\begin{array}{l}\text { Fixation preference } \\
\text { on paretic eye }\end{array}$ & $2(2.9)$ & $8(28.6)$ & $<0.01^{\mathrm{b}}$ \\
\hline Horizontal deviation & $15(21.4)$ & $8(28.6)$ & $0.31^{\mathrm{b}}$ \\
\hline Hypertropia at primary position, PD & $13.1 \pm 12.8$ & $13.0 \pm 9.1$ & $0.82^{\mathrm{a}}$ \\
\hline Scale of SOUA & $(5-35)$ & $(4-45)$ & $0.76^{\mathrm{a}}$ \\
& $1.7 \pm 0.8$ & $1.6 \pm 0.9$ & $0.23^{\mathrm{a}}$ \\
\hline Scale of IOOA & $(1-3.5)$ & $(1-3)$ & $0.03^{\mathrm{a}}$ \\
\hline Degree of excyclotorsion & $2.3 \pm 0.8$ & $2.5 \pm 0.8$ & $(1-4)$ \\
& $(0.5-3.5)$ & $1.9 \pm 0.64$ & $(1-4)$
\end{tabular}

${ }^{a}$ Mann-Whitney test ${ }^{b}$ Fisher's exact test, $\mathrm{PD}=$ prism diopters, $\mathrm{SOUA}=$ superior oblique underaction, $\mathrm{IOOA}=$ inferior oblique overaction 
Two patients (2.9\%) and eight patients (28.6\%) in the accordance and discordance groups, respectively, had a fixation preference in the paretic eye $(p<0.01)$. The preoperative degree of excyclotorsion $(2.3 \pm$ $0.67,1-4)$ in the accordance group was significantly greater than that in the discordance group (1.9 \pm $0.64,1-4)(p=0.03)$. Table 2 shows the clinical features in twp groups.

The postoperative excyclotorsion was $0.14 \pm 0.39(0-3)$ in the accordance group and $0.28 \pm 0.71(0-3)$ in the discordance group $(p=0.18)$. Fifty patients $(71.4 \%)$ in the accordance group and 11 patients $(39.3 \%)$ in the discordance group had a postoperative reduction with excyclotorsion $>1(p=0.01)$ (Table 3$)$.

Table 3

Postoperative results in the accordance and discordance groups

\begin{tabular}{|llll|}
\hline & Accordance group & Discordance group & $\mathbf{p}$ \\
\hline Hypertropia in the primary position, PD & $1.31 \pm 3.32$ & $1.06 \pm 2.61$ & $0.52^{\mathrm{a}}$ \\
\hline Scale of SOUA & $(0-10)$ & $(0-16)$ & $0.11^{\mathrm{a}}$ \\
\hline Scale of IOOA & $0.23 \pm 0.52$ & $0.12 \pm 0.23$ & \\
& $(0-3.5)$ & $(0-1.5)$ & $0.51^{\mathrm{a}}$ \\
\hline Degree of excyclotorsion & $0.15 \pm 0.37$ & $0.21 \pm 0.52$ & $0.18^{\mathrm{a}}$ \\
\hline Excyclotorsion reduction $(>1) \mathrm{n},(\%)$ & $(0-2)$ & $(0-1)$ & $0.01^{\mathrm{b}}$ \\
\hline Residual $(>1)$ excyclotorsion $\mathrm{n},(\%)$ & $0.14 \pm 0.39$ & $0.28 \pm 0.71$ & $0.01^{\mathrm{b}}$ \\
\hline $\begin{array}{l}\text { a Mann-Whitney test, }{ }^{\mathrm{b}} \text { Fisher's exact test, PD } \\
\text { IOOA = inferior oblique overaction }\end{array}$ & $(0-3)$ & $(0-3)$ & $11(39.3)$ \\
\hline
\end{tabular}

There were 14 patients (50\%) with a change in postoperative residual excyclotorsion $(>1)$ in the discordance group, compared with 16 patients $(22.9 \%)$ in the accordance group $(p=0.01)$. Table 3 shows the postoperative results in the accordance and discordance groups.

\section{Discussion}

Patients with USOP generally demonstrate hypertropia and excyclotorsion in the paretic eye. In this study, the excyclotorsion of USOP was more frequently observed in the paretic eye $(71.4 \%)$ than in the nonparetic eye (28.6\%). This is consistent with previous studies showing that $25 \%$ of cases of excyclotorsion could also be present in the non-paretic eye.[12, 13, 20]. 
In this study, the incidence of paradoxical ocular excyclotorsion in the non-paretic eye could be increased when patients had a fixation preference in the paretic eye or were aged < 2 years. Initially, paralysis of the superior oblique may lead to ocular excyclotorsion in the paretic eye, followed by ocular dominance [8], cyclofusion [15], or a neural adaptation mechanism [16] in the non-paretic eye, which can induce ocular excyclotorsion in either eye.

According to Kim et al.[14], the dominant eye could influence the alignment of the non-paretic eye through conjugate cycloversion eye movements. It has been demonstrated that neural adaptability for improving the efficiency of motor control and visual function may contribute to the torsional state in USOP. Prolonged fixation with the paretic dominant eye might act in a way that conversely decreases the amount of extortion in the eye, which induces excyclotorsion in the non-paretic eye through conjugate movements according to Hering's law.[17] Additionally, Kusher and Hairharan reported that long-term fixation with the affected eye in USOP could induce fundus torsional change in the affected eye.[21]

In this study, $42.9 \%$ of patients with excyclotorsion in the non-paretic eye were under 2 years of age. This result could be explained by the immature binocular visual system and sensory adaptation of children. A lack of immediate motor correction for torsional misalignment and defective binocular fusion in USOP may disrupt cyclofusion, which, in turn, induces the eye to be more excyclorotated, especially in the case of a non-paretic eye. Graf et al. demonstrated that the resting position of human eyes became more excyclorotated after disrupting binocular fusion with $8 \mathrm{~h}$ of prolonged monocular occlusion.[22] Shin et al. also demonstrated that a certain level of defective binocular fusion might disrupt cyclofusion and subsequently make the eyes more excyclorotated.[23]

In an effort to overcome vertical diplopia, patients with poor sensory adaptation, especially children, would have a greater need for vertical fusion. The immaturity of fusion would contribute to excycloduction in the non-paretic eye. Repetitive sensorial and motor adaptations to torsional misalignment aggravate fundus extorsion in patients with USOP under 2 years of age.

This study demonstrates that the reduction of excyclotorsion after surgery was larger in the accordance group than in the discordance group, consistent with the results of a previous study.[10] A possible explanation for this result might be a significant improvement in excyclotorsion in the paretic eye, which might be due to postoperative mechanical changes in the extraocular muscles, which has a direct effect on the torsional forces in the accordance group.

This study has a few limitations. First, it was conducted retrospectively, and most patients were pediatric patients. Second, although 98 patients were enrolled in this study, additional USOP patients might be needed to confirm the findings of this study. Third, the possibility of observer bias might exist for measurements of pre- and postoperative degrees of excyclotorsion using fundus examination in patients who were under 2 years of age.

In conclusion, the paretic eye may not coincide with excyclotorsion in USOP. Excyclotorsion in the nonparetic eye was observed in $28 \%$ of patients with USOP. Patients aged $<2$ years and with a fixation 
preference for the paretic eye might have a significantly greater propensity to undergo excyclotorsion in the non-paretic eye. Surgery for USOP can have a more obvious effect in improving excyclotorsion in the paretic eye.

\section{Contributors}

Study design (S.G.H); study conduct (S.H.K); data collection (E.H.C and S.G.H.); data analysis and interpretation (Y.W.S and S.G.H); and preparation, review, and approval of the manuscript (S.G.H, Y.W.S and S.H.K).

\section{Declarations}

\section{Funding}

The authors declare no competing interests.

\section{Competing interests}

The authors declare that they have no competing interests.

\section{Ethics approval and consent to participate}

The study was approved by institutional ethics board of Korea University Medical Center (NO K2021-

2736-001) and conducted in accordance with the tenets of the Declaration of Helsinki. Individual consent for this retrospective analysis was waived.

\section{Consent for publication}

Not applicable.

\section{Availability of data and materials}

The datasets used and/or analysed during the current study available from the corresponding author on reasonable request

\section{References}

1. Mollan S, Edwards J, Price A, Abbott J, Burdon M: Aetiology and outcomes of adult superior oblique palsies: a modern series. Eye 2009, 23(3):640-644.

2. Arici C, Oguz V: The effect of surgical treatment of superior oblique muscle palsy on ocular torsion. Journal of American Association for Pediatric Ophthalmology and Strabismus 2012, 16(1):21-25.

3. Helveston EM, Mora J, Lipsky S, Plager D, Ellis F, Sprunger D, Sondhi N: Surgical treatment of superior oblique palsy. Trans Am Ophthalmol Soc 1996, 94:315. 
4. Simons B, Saunders T, Siatkowski R, Feuer W, Lavina A, Capó H, Munoz M, Flynn J: Outcome of surgical management of superior oblique palsy: a study of 123 cases. Binocul Vis Strabismus $Q$ 1998, 13(4):273-282.

5. Von Noorden GK, Murray E, Wong SY: Superior oblique paralysis: a review of 270 cases. Arch Ophthalmol 1986, 104(12):1771-1776.

6. HELVESTON EM: Diagnosis and management of superior oblique palsy. Int Ophthalmol Clin 1985, 25(4):69-77.

7. Lee JE, Yang HK, Kim JH, Hwang J-M: Quantitative analysis of structure-function relationship between ocular motility and superior oblique muscle hypoplasia in unilateral superior oblique palsy. Br J Ophthalmol 2019, 103(9):1253-1258.

8. Wang Y, Wu Q, Jiang J-J, Li H, Liu W, Li C, Bai X-Q, Li N-D: Effect of unilateral inferior oblique weakening on fundus torsion in bilateral eyes of children with congenital superior oblique palsy. International Journal of Ophthalmology 2020, 13(10):1637.

9. Kwon HG, Lee SY, Lee YC: Superior oblique palsy combined with horizontal strabismus. J Korean Ophthalmol Soc 2003, 44(8):1846-1851.

10. Lee J-Y, Kim HJ, Park K-A, Oh SY, Oh SY: Clinical characteristics according to the laterality of ocular torsion in unilateral superior oblique palsy. BMC Ophthalmo/ 2018, 18(1):1-6.

11. Lee JJ, Chun KI, Baek S-H, Kim US: Relationship of hypertropia and excyclotorsion in superior oblique palsy. Korean J Ophthalmo/ 2013, 27(1):39.

12. Na KS, Lee SY, Lee YC: Ocular torsion in unilateral superior oblique palsy. J Korean Ophthalmol Soc 2007, 48(10):1388-1393.

13. Olivier $P$, von Noorden GK: Excyclotropia of the nonparetic eye in unilateral superior oblique muscle paralysis. Am J Ophthalmol 1982, 93(1):30-33.

14. Kim DH, Kim H, Lim HT: The influence of ocular sighting dominance on fundus torsion in patients with unilateral congenital superior oblique palsy. Graefe's Archive for Clinical and Experimental Ophthalmology 2017, 255(12):2473-2479.

15. Straumann D, Steffen H, Landau K, Bergamin O, Mudgil AV, Walker MF, Guyton DL, Zee DS: Primary position and Listing's law in acquired and congenital trochlear nerve palsy. Invest Ophthalmol Vis Sci 2003, 44(10):4282-4292.

16. Wong AM: Listing's law: clinical significance and implications for neural control. Surv Ophthalmol 2004, 49(6):563-575.

17. Wong AM, Sharpe JA, Tweed D: Adaptive neural mechanism for Listing's law revealed in patients with fourth nerve palsy. Invest Ophthalmol Vis Sci 2002, 43(6):1796-1803.

18. Hakim OM: Association between fixation preference testing and strabismic pseudoamblyopia. In.: Slack Incorporated Thorofare, NJ; 2007.

19. Guyton DL: Clinical assessment of ocular torsion. Am Orthopt J 1983, 33(1):7-15. 
20. Lefevre F, Pechereau A: Study of optic nerve head-fovea angle with retinophotography in congenital fourth nerve palsy. J Fr Ophtalmol 2009, 32(4):263-267.

21. Kushner BJ, Hariharan L: Observations about objective and subjective ocular torsion. Ophthalmology 2009, 116(10):2001-2010.

22. Graf EW, Maxwell JS, Schor CM: Changes in cyclotorsion and vertical eye alignment during prolonged monocular occlusion. Vision Res 2002, 42(9):1185-1194.

23. Shin KH, Lee HJ, Lim HT: Ocular torsion among patients with intermittent exotropia: relationships with disease severity factors. Am J Ophthalmol 2013, 155(1):177-182. 